\title{
Ars computistica ancilla artis editionum Modern IT in the service of editors of (Greek) texts*
}

\author{
Charalambos Dendrinos and Philip Taylor \\ Royal Holloway, London, Great Britain
}

Almost two decades ago, a Festschrift was published in honour of the
distinguished Hellenist, Byzantinist and Palaeographer, the late Robert
Browning (I9I4-I997), whose work on Greek manuscripts and
editions of Byzantine texts has left an indelible mark in our field. In his
important article included in that volume, Professor Evangelos Chrysos

This lecture was given on 3 April 2014 at Stockholm University.

* This article was written with the cooperation of Philip Taylor for the technical part (see Part II). The work presented above is the result of close and fruitful collaboration. Grateful thanks are offered to the following institutions: the British Library for their co-operation and support in providing us with high-resolution digital images of the Royal MS I6 C X, and for their kind permission to reproduce them in our edition; the Thesaurus Linguae Graecae ${ }^{\circledR}$ Digital Library Project at the University of California, Irvine, the Perseus Digital Library Project at Tufts University, and The Archimedes Digital Research Library Project, a joint endeavour of the Classics Department at Harvard University, the Max Planck Institute for the History of Science (MPIWG) in Berlin, the English Department at the University of Missouri at Kansas City, and the aforementioned Perseus Digital Library Project, for their kind permission to link our edition with entries in their online Liddell-Scott-Jones, Greek-English Lexicon and Lewis and Short, Latin Dictionary. We are pleased to gratefully acknowledge the financial help we have received for this phase of the Project from the Hellenic Institute and the Faculty of Arts and Social Sciences Research Initiative Fund at Royal Holloway, University of London, and from a donor who wishes to remain anonymous.

Our deepest thanks go to the members of our team, whose dedication, enthusiasm and hard work on both scholarly and technical aspects made the timely completion of this project possible: Dr Annaclara Cataldi Palau, Michalis Konstantinou-Rizos, Dr Konstantinos Palaiologos, Dr Vasos Pasiourtides, Rob Turner, and Dr Christopher Wright. We would also like to express our warmest thanks to Dr Scot McKendrick, Head of History and Classics at the British Library, for his co-operation and scholarly contribution, and to Professor Caroline Macé for her co-operation and support in the preliminary phase of the project.

How to cite this book chapter:

Dendrinos, C. and Taylor, P. 20I6. Ars computistica ancilla artis editionum: Modern IT in the service of editors of (Greek) texts. In: Crostini, B., Iversen, G. and Jensen, B. M. (eds.) Ars Edendi Lecture Series, vol. IV. Pp. 85-1 I6. Stockholm: Stockholm University Press. DOI: http://dx.doi.org/Io.I6993/baj.e. License: CC-BY 4.0 
reflected on the use of Information Technology as an educational and research tool in Byzantine Studies from the beginning of computing applications up to that point in time. ${ }^{\mathrm{I}}$ Describing the response by the scholarly community to the use of computers at that early stage, he distinguished various attitudes, ranging from the 'virgin's stance', reflecting fear and suspicion towards technological tools, considered unsuitable for traditional, serious scholarship; the 'Sisyphus syndrome', describing a sense of impasse in the endless struggle to reconcile incompatible hardware and software technologies; the 'Eleusinian syndrome', shared among the devotees of a close circle of scholars, whose expertise in informatics elevated them to the status of 'initiators to modern mysteries'; to the 'grab's motion', representing those who felt that only slowly perhaps some software applications could eventually be used in, or even created for, the humanities; the 'publish in print or perish' view, which degraded the production of electronic and multimedia applications and databases in terms of scholarly value; and finally, what Professor Chrysos called the 'Trithemius attitude'.

Trithemius is not an unfamiliar name to readers of the present Lecture Series. It was Professor Jan M. Ziolkowski who mentioned Johannes Trithemius (John of Trittenheim, I462-I5I6) in his article included in the first volume of this Series. ${ }^{2}$ Both Professor Chrysos and Professor Ziolkowski, among other scholars, ${ }^{3}$ drew attention to Trithemius's treatise De laude scriptorum manualium, which he wrote in I492, almost four decades after Johannes Gutenberg printed the Bible in Mainz ( $1454 / 5)$ using a movable-type press. In his treatise, the Benedictine abbot reflected on the spiritual and practical value of writing and copying for the monk as opposed to the production of the printed book. Ironically, the treatise does not survive in manuscript form but only in printed copies; it was first published in I494, while a revised edition appeared in I $497 .{ }^{4}$ As Professor Ziolkowski judiciously remarked, Trithemius's case is analogous to the 'posting online, or blogging, or tweeting [of a] stout defence of conventional publication' today. Trithemius eventually realised the potential benefits of typography for education and scholarship, and changed his mind, openly expressing his appreciation of printing, which he elevated to 'ars illa mirabilis \& prius inaudita imprimendi \& characterizandi libros'.

Trithemius is an enlightened guide for scholars who, though holding old-fashioned scholarship close to heart and mind, are prepared to make 
good use of the advantages of the rapid advances in technology for the pursuit of learning and teaching, combining tradition and innovation. Judging from the ever-increasing number of on-going projects in digital humanities being conducted at present, as if foreseeing the future Trithemius was entirely justified to include, among the major disciplines a monk ought to master, 'theologia, musica, iura et ars computistica' (the latter actually in the sense of chronology). ${ }^{6}$ Let us see how, in our case, the ars computistica (in its modern sense) can act as bona ancilla to the ars editionum. In other words, how modern Information Technology can help us in responding to the challenges of editing and publishing texts, especially mediaeval, and Greek in particular. ${ }^{7}$

At the invitation of Dr Antonia Giannouli (University of Cyprus) and Dr Elisabeth Schiffer (Austrian Academy of Sciences), a group of scholars met at the International Workshop on Textual Criticism and Editorial Practice for Byzantine Texts held in Vienna in December 2009. Among the various issues discussed were the progress of digital humanities and the potential benefits of online electronic editions, especially of autograph Greek texts, in terms of interactive presentation and wide dissemination. ${ }^{8}$ The task of exploring the possibilities and limitations of such an approach was subsequently undertaken by a team of scholars, postgraduate students and technical advisors at the Hellenic Institute of Royal Holloway, University of London, in close collaboration with the British Library. It was suggested at the time that this edition should be presented to H.M. Queen Elizabeth II as part of the celebrations of her Diamond Jubilee. For this reason, the text selected combines a number of elements: it is unpublished, autograph and written in Greek, it survives in a unique manuscript in the Royal Collection in the British Library (MS I6 C X), and is related to the history of Hellenic Studies in Britain. In addition, it is dedicated to Queen Elizabeth II's distinguished homonymous predecessor, Queen Elizabeth I. What we had not anticipated at this early stage were the circumstances in which the edition would be finally presented to our Royal honorand, as we shall see.

The text is an Encomium on King Henry VIII (I 509-I 547), addressed to his daughter Queen Elizabeth I (I558-I603) with the intention of presenting it to her on the occasion of her Royal Visit to Oxford in I 566. Another important manuscript related to this event is preserved in the Bodleian Library in Oxford, MS Bodley I 3 a, which gives a unique account of the famous buildings of the University, illustrated by 
a series of pen drawings by John Bereblock, Fellow of Exeter College. ${ }^{9}$ Composed in Latin verse by Thomas Neale, Regius Professor of Hebrew, the account is presented in the form of a fictitious dialogue between Elizabeth and the Chancellor of the University, Robert Dudley, Earl of Leicester, who guides her on an imaginary tour around Oxford Colleges, and takes the opportunity to praise their founders for their generosity, thus encouraging the Queen to imitate them. Though Elizabeth was not persuaded to establish a College in Oxford, this manuscript gives us an insight into the workings of patronage and endowment in Elizabethan times.

A vivid description of the Royal Visit was also given by Penry Williams. ${ }^{\circ}$ Among the representatives of the city and the university who gave a series of orations in honour of Elizabeth during the course of her stay at Oxford was Giles Lawrence (I 522-I 584/5), a native of Gloucester and Regius Professor of Greek at Oxford University (I 55 I-I 53 and I 5 59-I 584/5). His oration, delivered to the Queen in Greek, received a short response by Elizabeth, also in Greek. Lawrence's oration, however, is not the text being edited here. The text chosen for editing is an oration that would have been delivered by George Etheridge, former Professor of Greek at Oxford (I 547-I 550 and I 5 53-I 559 ), had he not been expelled from this post seven years earlier (I 559 ).

George Etheridge was born in Thame, Oxfordshire, in I519, and received his education at the University of Oxford. ${ }^{11}$ He studied under John Shepreve at Corpus Christi ( I 534-I 539). After he received his BA he was appointed a probationary Fellow and in I 54I his post was made permanent. A master of the three humanistic languages - Greek, Latin and Hebrew-, Etheridge published a number of works including a Greek translation of the second book of the Aeneid, a Latin translation of the works of Justin Martyr and a devotional text on Saint Demetrios. He also composed verses in Hebrew based on the Psalms, and in Greek on Thomas Wyatt's Protestant conspiracy and revolt against Mary I, clearly an attempt on Etheridge's part to win royal favour and revealing of his strong Catholic convictions. The last book Etheridge published, in I 588 , is a Latin medical textbook based on Paul of Aegina. This work, which reflects his interest in medicine, is accompanied by an introduction in Greek and verses in Latin and Greek, where he expresses his appreciation to the learned physicians of Oxford for the help he had received from them and for their knowledge of Greek.

From an early stage of his academic life, Etheridge was involved in religious controversy. Though he was prepared to accept Henry's breach 
with Rome in order to secure his University post at the beginning of his career, with the advance of the Protestant Reformation he refused the return of the Royal Supremacy under Elizabeth, as did other scholars. His religious convictions led to his arrest and questioning in $156 \mathrm{I}$. Expelled from his post, receiving no regular income and persecuted by the authorities, Etheridge composed his Encomium on Henry in an attempt to win Elizabeth's favour during her Royal Visit to Oxford ( I 566). Whether the Queen ever read this Encomium remains unknown. What is certain is that its purpose was never fulfilled, as Etheridge was not restored to his post.

The autograph Encomium is composed in blank verse, written in classical and primarily Homeric Greek which reflects the epic character of its subject, the heroic deeds and virtues of Henry. It is directly addressed to Elizabeth. In his preface, Etheridge praises the Queen's education and knowledge of Greek (ff. Ir-v). The preface is followed by a summary of its content in Latin (ff. $5 \mathrm{r}-6 \mathrm{r}$ ). Apart from quotations from the Iliad, and to a lesser extent from the Odyssey, Etheridge alludes to the Platonic philosopher king (f. 2ov), a most appropriate image of the ideal monarch, and Plutarch's Life of Artaxerxes (ff. 4r, $36 \mathrm{v}-37 \mathrm{r})$. He also makes extensive use of Scriptural quotations, refers to Greek theological works of Justin Martyr (f. 3 Ir), which he had translated into Latin, and lists other Church fathers including Cyprian, John Chrysostom, Basil of Caesarea and Gregory of Nazianzus (f. I9v).

The encomium devotes a large part to Henry's military achievements, including the two campaigns against the French, both of which he commanded in person (ff. $8 \mathrm{~V}-\mathrm{I} 3 \mathrm{~V}$ ). Henry is presented as the synthesis of the four Platonic virtues (courage, justice, prudence and wisdom) and the qualities of a peaceful ruler (including clemency, moderation and philanthropia) (ff. $8 \mathrm{r}-\mathrm{v}, 22 \mathrm{v}-27 \mathrm{r}$ ), which complement his martial prowess - themes typical of Mirrors of Princes. Remarks on Henry's preferment of obedience through reason and persuasion rather than fear (f. I 5 r) reflect Etheridge's concerns regarding his own situation. By stressing the value of education and commending Henry as a patron of academia and of the author himself —even mentioning what salary he used to receive as Regius Professor (f. I9r) - Etheridge serves his own aims and at the same time invites Elizabeth to continue her father's legacy promoting scholarship (ff. I 8r-2 Ir, 24r, 25r, $35 \mathrm{v}-37 \mathrm{r}$ ).

In the latter part of the text, Etheridge appeals to Elizabeth, touching upon the sensitive issue of her succession, voicing the national concern relating to the security of the kingdom through an heir to the throne, thus 
confirming his own allegiance to her and her successors (ff. $28 \mathrm{v}-3$ or). [http://www.rhul.ac.uk/Hellenic-Institute/Research/Etheridge/Authorand-Text/Text.html - ftn39] He closes the encomium by exhorting Elizabeth to continue her father's legacy by supporting and promoting scholarship, and by acting mercifully towards him.

This short autograph rhetorical text adds to our knowledge of Greek Studies in Tudor England in general and of George Etheridge and Henry's cultural politics in particular. By editing this Encomium electronically, we aimed at offering a new resource to the academic community while at the same time providing a useful educational tool accessible also to the general public, free of charge. Although aware of existing work in the field, especially The Codex Sinaiticus Project at the British Library, ${ }^{\mathrm{I}}{ }^{2}$ we opted to begin from scratch in order to explore the possibilities free from the constraints that would have been imposed by any attempt to replicate or perhaps just improve existing methods. In the process, we have been developing new ideas and techniques and addressing numerous questions, not all of which have yet found a satisfactory answer. Similarly, not all ideas and suggestions we have received from colleagues and students have been fully explored or applied. It is essential for the success of our project to continue developing, experimenting, sharing and inviting new approaches and practices concerning both conventional and electronic editing of texts.

Turning now to the technical aspects of our edition, the Encomium which forms the basis of this project, as mentioned above, survives in a unique autograph manuscript. This considerably simplifies some of the technical issues involved in its electronic presentation. In particular, we have not had to address the complications which would have arisen had we been forced to present more than one manuscript variant. The online edition quite deliberately makes use of only well-established and proven non-proprietary web technologies (HTML 4.OI, CSS and JavaScript) and should therefore be accessible from any modern web browser; a "debug" option is provided to facilitate the reporting and diagnosis of any errors encountered.

In the opening web page we have placed (on the left-hand side) navigation aids that expand to allow access to the supplementary material and (on the right-hand side) the image of the first folio of the manuscript which gives access to the edition (Figure I). ${ }^{\mathrm{I}}$ If we start by looking at the electronic edition of the manuscript, we see that the facsimile image of the manuscript is presented on the left-hand side of the screen, while on the right is displayed either the transcription of the text, or an edition 
of the text, with or without line numbers, and with different possible reflows. We also provide an English translation of the text.

The benefits of juxtaposing the digital images of the manuscript with the transcription and edition, and to a lesser extent with the translation, are, we believe, self-evident, and we take advantage of this parallel presentation by providing a two-way visual linking between a word or phrase in the manuscript and the corresponding word or phrase in the text. This technique is intended to help the user in interpreting the script, with its many ligatures and abbreviations. If we move the mouse cursor over any word in the image, both that word and the corresponding word in the facing text are highlighted in red, and if we move the mouse over any word in the text, exactly the same behaviour occurs. In the case of the translation, it is not possible to achieve this kind of precise word-for-word matching, as we have deliberately produced an idiomatic translation rather than simply translating mechanically on a word-to-word basis; the linking within the translation is therefore on a phrase-by-phrase basis.

In order to aid palaeographical training, we have opted for a diplomatic transcription exactly matching the style of script of the manuscript; so, for example, where letters or words have been written as superscript in the manuscript, this disposition is replicated in the transcription. An example can be seen at $\mathrm{f}$. $4 \mathrm{r}$, where we have the interlinear addition of the two words $\mu \tilde{\alpha} \lambda \lambda$ ov $\mu \mu \varepsilon \tilde{\varepsilon} \sigma \theta \alpha l$ on line 5 . The fact that an electronic presentation enables us to offer different variants of the text alongside the facsimile means that we can emphasise this visual correspondence in the transcription, reserving normalisation of the text solely for the edition. However, in order to clarify the meaning of the text, we have intervened in the transcription by expanding abbreviations as, for example, in the case of the word $k \alpha i$ in line I I, thus following normal editorial practice.

The edition is equipped with an apparatus criticus and an apparatus fontium. Words with apparatus criticus entries attached to them are identified by being displayed in a different colour; this colour is currently green, but we may change this in the future in order to improve access for those with red-green colour blindness. If we hover the mouse pointer over such a region for more than a moment, a small pop-out appears containing an editorial note. In line 2 , for example, Etheridge has written the word $\dot{\eta} \gamma o \tilde{v} \mu \alpha l$ with a smooth rather than a rough breathing, and the editorial emendation is glossed in the accompanying note. In the case of the apparatus fontium, we use a footnote-type mark. If we click on such a mark, it will cause the corresponding note to be displayed in the 
footnote area, while a second click will dismiss it. Apparatus fontium notes also accompany the translation, and can be displayed in exactly the same way.

In addition, the translation is accompanied by a commentary which sets out to elucidate the text, and this appears in a separate sequence of notes which are triggered in a similar manner. In $\mathrm{f}$. Iv, for example, we see a note ${ }^{(a)}$ with information on Elizabeth I's education: she was taught by William Grindall and Roger Ascham, and her study of Greek texts included Sophocles and Isocrates as well as the Greek New Testament. According to Asham, Elizabeth spoke her Greek 'frequently, willingly and moderately well'!

Apart from these aspects, we try to assist the user in interpreting the text by supplying each word in the transcription and edition with a brief lexicographical analysis. If we click on any Greek word (for instance, $\pi \alpha l \delta \varepsilon i \alpha \varsigma$ in $\mathrm{f}$. IV, line 3 ) a note appears at the bottom of the page. This note shows the form in which the word appears in the text, parses it and also indicates its lemma form. In addition, it offers links to corresponding entries in three online dictionaries (Archimedes Lexicon, the online Liddell-Scott Jones Lexicon provided by Perseus, and the same lexicon from the Thesaurus Linguae Graecae), whose administrators have kindly allowed us to hot-link to their content in this way. A click on the link will display the entry on the left-hand side of the screen, temporarily overlaying the manuscript image. The latter two online dictionaries are themselves linked with the cited Greek texts, for those who wish to explore further.

In designing the infrastructure to support the electronic edition, we had a number of desiderata in mind; these, and the accompanying code fragments illustrating how they were accomplished, are presented here as succinctly as possible, as it is appreciated that these aspects of the project may be of interest to only a minority of readers of this volume. Nonetheless, we feel that the details are worth recording, as they may save others considerable time if they decide to attempt a similar project (see Appendix below).

Returning to the project as a whole, supplementary material is provided on the website to help to place the manuscript, the text and our edition in the wider context. This material includes an article by Dr Scot McKendrick on the Greek manuscript collections of the British Library, providing links to descriptions and digital images of a number of manuscripts they contain. ${ }^{\mathrm{I}}$ Dr Christopher Wright's articles on the 
Author and the Text shed light on Etheridge's life, personality and work, and analyses and evaluates the Encomium. ${ }^{\mathrm{Is}}$ The Royal MS I6 C X is described by Dr Annaclara Cataldi Palau, including links to specific folia and to other related manuscripts and sites. ${ }^{16}$ A separate option gives access to the British Library Digitisation page, which includes a zoomable image of the manuscript. ${ }^{17}$ Other options offer guidelines on how to use the edition, ${ }^{18}$ a presentation of our editorial principles, ${ }^{19}$ and implementation details for those who would like to know more about the technical aspects of the methods employed. ${ }^{20}$

We view this work very much as an on-going exploratory, interactive editorial project which, as with all such projects, has assumed a life of its own. Our hope is that in the future it will keep growing, developing and maturing, with the help of experts and non-experts alike, who will be willing to share their thoughts and work with us in order to help improve it further. It is just as important for us that members of the public are involved in this project, with the ability to offer their comments, ideas and suggestions on how to make this and similar editions more accessible, readable, useful and indeed more enjoyable, without compromising quality in terms of scholarship. For this reason, as mentioned above, we have provided a semi-automated feedback feature. In order to send feedback, all that is necessary is to highlight the word or phrase on which one wishes to comment, and click [Feedback]. The text is automatically copied into the appropriate field of the web form, so all one has to do is to add a comment and the commentator's e-mail address and click [Submit feedback] to send it to us.

The next step in our Project will be to convert the written text into the spoken word, completing a full circle from its inception, to its written composition, and to its oral delivery, something of which we hope that Etheridge himself might have approved. This aspect raises questions concerning pronunciation, which was a matter of considerable controversy in sixteenth-century English academia. At that time, the scholarly world was divided between the advocates of the traditional pronunciation of Greek, which is virtually the same pronunciation still used by Greeks today, and which was at that time associated with Catholic and conservative circles; and the advocates of the then-new 'Erasmian' system, which was adopted by the humanists and Protestant reformers and which became established in England with Elizabeth's accession to the throne in $155^{8 .} .^{21}$ Etheridge's own convictions, and internal evidence in the text (in particular, errors of itacisms and faulty breathings), suggest that he almost certainly used 
the traditional pronunciation, which, rather confusingly, is also called the 'modern' pronunciation.

Even when all issues of pronunciation have been resolved, to produce a synchronised recording of the text is not an easy task. The main reason for this is that it requires the automated determination of word boundaries in spoken Greek, something which we believe has never previously been attempted. However, with the advice, assistance and encouragement of Professors Jiahong Yuan and Mark Liberman (University of Pennsylvania), and Professor Amalia Arvaniti (University of Kent), we have made a successful start at this. ${ }^{22}$ Looking to the future, a major step will be to experiment with the edition of a Greek text transmitted in more than one manuscript, which has so far proved a major challenge.

\section{PART II}

Desiderata (presentation)

- Simple and flexible navigation, with consistent placement and appearance of navigation aids

- Parallel presentation: MS facsimile left; text (edition, transcription or translation) right

- Interlinked highlighting: corresponding words (or phrases) highlighted simultaneously in MS facsimile and in text on mouseover

- Brief lexicographical analysis of word displayed in footnote area when word is clicked in text

- Lexicographical analyses linked to one or more external e-lexica for additional information

- E-lexicon content should temporarily overlay MS facsimile, and be dismissed by either [View MS] button or further click on lexicon link

- Existence of scholarly apparatus indicated by text colour (apparatus criticus) or superscript (apparatus fontium, apparatus referentium, apparatus scholiarum)

- Stretch of text to which scholarly apparatus applies indicated by underlining in text while apparatus is displayed

- Simple feedback mechanism that automatically embeds any highlighted text, together with current view state

- View state can be bookmarked (required for above)

- Optional line-numbering

- Vertically and horizontally centered display that gracefully accommodates varying degrees of zoom 
Desiderata (technical)

- Standards-compliant code (Validated HTML 4.0I Strict, CSS 2/3, JavaScript)

- Browser independence: coded to perform as near as possible identically in all modern browsers

- Minimal markup (DOM analysis on page load, attributes added dynamically where possible)

- Use AJAX (XMLHttpRequest) wherever possible (i.e., other than cross-domain requests)

- Minimal dependence on libraries; no use of large libraries such as jQuery or similar

Desiderata (edition)

- Tri-state reflow: none, normal, full

- Editorial interventions (with concealed apparatus criticus) indicated by change of text colour (currently green)

- Apparatus criticus displayed as temporary boxed overlay ("tooltip") on mouseover of marked text

- Existence of apparatus fontium indicated by superscripted Arabic number, apparatus displayed in footnote area when callout clicked

- Existence of apparatus referentium indicated by superscripted lower-case Roman number, apparatus displayed in footnote area when callout clicked

\section{Desiderata (translation)}

- Simultaneous highlighting by phrase rather than by word

- Phrases that span folio boundaries set off by chevrons

- Existence of apparatus fontium indicated by superscript Arabic number, apparatus displayed in footnote area when callout clicked

- Existence of apparatus referentium indicated by superscript lowercase Roman number, apparatus displayed in footnote area when callout clicked

- Existence of commentaries ("Apparatus scholia") indicated by superscript lower-case letter, commentary displayed in footnote area when callout clicked 
Desiderata (adjunct material)

- Uniform style of presentation, enforced by use of Macromedia Dreamweaver template

- "Accordion"-style menu with bi-stable expansion/contraction

- When jumping to a footnote, individual footnote should be discreetly highlighted to enable it to be easily identified, and a return from the footnote should be possible by clicking on the footnote itself rather than requiring, for example, the use of the browser "Back" button

The methods by which some of the more important of these aims were accomplished can be summarised as follows:

\section{Simultaneous highlighting (image)}

- The visible (sepia) MS facsimile is overlaid with a number of invisible identical red clones

- Each word in the transcription and edition is tagged with lineand word-number (in the translation, phrases are tagged)

- During DOM traversal, an "onmouseover" event handler is grafted onto each of these elements

- When the event handler fires, the rectangular region(s) in the hidden graphic overlays which correspond to the active line- and word-number (or active phrase) are revealed

- A subsequent "onmouseout" event restores the status ante bellum

The markup used to accomplish this is shown below. Note that the $<\mathrm{B}>$ elements, corresponding to words in the transcription and edition and to phrases in the translation, are not rendered in bold; the $<\mathrm{B}>$ element is $(\mathrm{ab})$ used simply because its tag is as short as possible, consisting of a single letter, and the element is not otherwise needed (modern semantic markup uses <strong $>$ ).

Folio 1 recto (transcription)

$$
\begin{aligned}
& <\text { DIV id="Transcription" class="Transcription" }> \\
& <\mathrm{P}> \\
& <\text { SPAN }>
\end{aligned}
$$

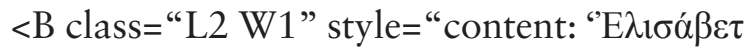

$$
\begin{aligned}
& \text { (dative)" " >'E } \lambda \imath \sigma \alpha ́ \beta \varepsilon \tau</ \mathrm{B}>\text {, } \\
& <\text { B class="L2 W2" }>\tau \text { o } \delta \grave{i}</ \text { B }>
\end{aligned}
$$




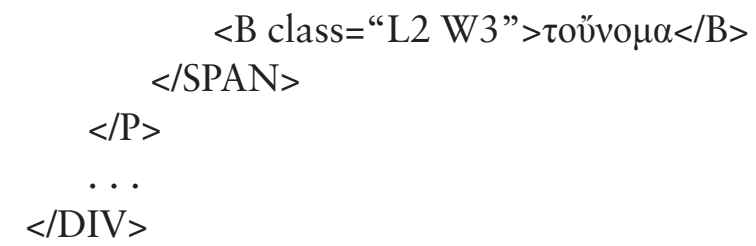

Folio 1 recto (translation)

$<$ DIV id="Translation" class="Translation fIr" > $<\mathrm{P}>$

$<$ B class= "RI" $>$ To the most honoured and famous Elizabeth $</ \mathrm{B}>$, $<$ B class $=$ "R2" $>$ First of that name $<$ B $>$, $<$ B class= "R3" $>$ Queen of England, France, Ireland, etc $</ B>$ :

$<$ B class= "R 5 " $>$ act rightly and prosper $</ \mathrm{B}>$ !

$<$ B class="R4" $>$ George Etheridge, physician $</ B>$. $</ \mathrm{P}>$

$</ \mathrm{DIV}>$

\section{Simultaneous highlighting (text)}

- Each word in the MS facsimile is partitioned into a number of (possibly overlapping) rectangular areas

- Each area contains a part or the whole of exactly one word, and is tagged with line-, word- and region number

- Taken together, the set of areas constitutes an HTML <MAP> element

- During DOM traversal, an "onmouseover" event handler is associated with each area

- When the event handler fires, the word in the text that corresponds to the active line- and word-number has its current colour recorded, and its colour is then set to red

- A subsequent "onmouseout" event restores the status ante bellum.

The process can most easily be visualised by examining each of the four pairs of plates below:

Folio $1 \mathrm{r}$, showing map areas

- (Figure 2) fir.jpg

- (Figure 3) fir-mapped.jpg 
Fol. 1r (detail), showing map areas

- (Figure 4) fir-detail.jpg

- (Figure 5) fir-detail-mapped.jpg

Fol. 1r (detail), showing mask

- (Figure 6) fir-detail-mask.jpg

- (Figure 7) fir-detail-mapped-mask.jpg

Fol. 1r (detail), one word highlit

- (Figure 7) fir-detail-mapped-mask.jpg

- (Figure 8) fIr-detail-highlit.jpg

Simultaneous highlighting (inter-linking of text and image)

- In addition to changing the colour of the corresponding word in the facing panel, an "onmouseover" event in the graphics pane changes the colour of the active word in the graphics pane using the same procedure as was outlined above in "Simultaneous highlighting (image)"

- In addition to changing the colour of the corresponding word in the facing panel, an "onmouseover" event in the text pane changes the colour of the active word in the text pane using the same procedure as was outlined above in "Simultaneous highlighting (text)"

The JavaScript which accomplishes this is as follows:

Mouse handler for text

Mouse.Active. Over.Text = function (Element)

Global.LastEvent = "Mouse. Over.Text"

Element.onmouseout $=$ function ()

\{

Global.LastEvent = "Mouse. Out.Text"

Conceal (Element)

Restore (Element)

\}

Highlight (Element)

Disclose (Element) 
Mouse handlers for folio image

Mouse.Active. Over.Folio = function (Element)

Global.LastEvent $=$ "Mouse.Over.Folio"

Disclose (Element)

Highlight (Element)

\}

Mouse. Active. Out.Folio = function (Element)

\{

Global.LastEvent $=$ "Mouse. Out.Folio"

Restore (Element)

Conceal (Element)

\}

Lexicographical analyses

- During initialisation, a lexicon (for the Greek) and a dictionarium (for the Latin) are read into internal data structures

- Each entry in these contains a headword, lexicographical analysis, and keywords that allow it to be looked up in external lexica

- During DOM traversal, an "onclick" handler is grafted onto each word in the text

- When the handler is invoked, a content-addressable search of the data structures is conducted, and the record returned is used to populate a region in the footnote area

- A further "onclick" on the same word conceals the entry in the footnote area, while an "onclick" on a different word causes the lexicographical information for that word to replace the former information.

\section{External lexica}

- When a lexicographical record is retrieved, HTML elements are wrapped around the external lexica components of the record to render them active and to associate an "onclick" handler with each

- In addition, the Unicode used internally is dynamically converted to Betacode for those external lexica that are still dependent on this encoding

- When the "onclick" handler is invoked, an attempt is made to retrieve the corresponding record from an external lexicon by 
making the associated URL the "src" attribute of an <IFRAME> element contained within an otherwise concealed $\langle$ DIV $>$ that overlays the MS facsimile; this $<\mathrm{DIV}>$ is then made visible

- A further click on the link (or on the [View MS] button) renders the $<$ DIV $>$ invisible again, re-disclosing the MS facsimile

\section{Apparatus criticus}

- When the text for the edition of a folio is prepared, editorial emendations are wrapped in $<$ SPAN class="Apparatus criticus" $>$ elements

- During initialisation, an external file containing the apparatus criticus for the entire MS is read in and used to populate an internal data structure

- During DOM traversal, the $<\mathrm{SPAN}$. . .> elements have an "onmouseover" handler associated with them

- When this handler is activated, the corresponding entry is retrieved using folio, face and $A C$ ordinal as keys, HTML elements are interpolated, and the record is displayed as a tooltip using Erik Bosrup's "Overlib" library

- When the mouse leaves the region of the $<$ SPAN . . .> element, the status ante bellum is restored

\section{Markup and data for apparatus criticus}

$<\mathrm{P}>$

$<$ B class= "L9 WI" $>A \mu \varphi о \tau \varepsilon ́ \rho \omega v</ B>$

$<$ B class="L9 W2" $>\varepsilon \check{v} v \varepsilon \kappa \alpha</ \mathrm{B}>$,

$<$ B class= "L9 W3" $>\tilde{\omega}</ \mathrm{B}>$

$<$ SPAN class="Apparatus criticus" $>$

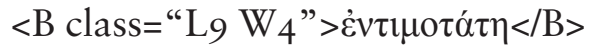

$</$ SPAN $>$

$</ \mathrm{P}>$

["foo Ir", "AC-I", “<I>corr.: </I $>\dot{\varepsilon} \mu \varphi \alpha v \varepsilon ́ \sigma \tau \alpha \tau \eta \mid \mathrm{I}>\operatorname{cod} .</ \mathrm{I}>$ ”],

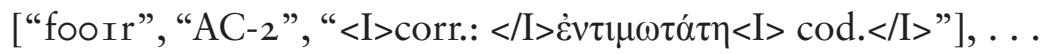

\section{Apparatus fontium}

- When the text for the edition of a folio is prepared, direct quotations from other authors are wrapped in <SPAN class="Apparatus fontium" > elements 
- During initialisation, an external file containing the apparatus fontium for the entire MS is read in and used to populate an internal data structure

- During DOM traversal, the $<\mathrm{SPAN}$...> elements have a trailing superscript with associated "onclick" handler grafted on

- When this handler is activated, the corresponding entry is retrieved using folio, face and AF ordinal as keys, HTML elements are interpolated, and the record is displayed in the footnote area

- If the superscript is clicked a second time, the status ante bellum is restored

Markup and data for apparatus fontium

$$
<\mathrm{P}>
$$

$<\mathrm{B}$ class= "L4 WI" $>A \rho \tau \alpha \xi \dot{\varepsilon} \rho \xi \eta \eta / \mathrm{B}>$

$<$ B class="L4 W/ 2 " style=" content: ' $\tau$ ò (accusative)" " $>$ ò $</ \mathrm{B}>$

$<$ SPAN class="Apparatus fontium" $>$

$<$ B class= " $\mathrm{L}_{4} \mathrm{~W}_{3}$ " $>\mu \tilde{\eta} \lambda \mathrm{ov}</ \mathrm{B}>$

$<\mathrm{B}$ class= "L4 $\mathrm{W}_{4}$ " $>\dot{v} \pi \varepsilon \rho \varphi v \dot{\varepsilon} \zeta</ \mathrm{B}>$

$<\mathrm{B}$ class $=$ "L4 W 5 " $>\mu \varepsilon \gamma \varepsilon \dot{\varepsilon} \theta \varepsilon 1</ \mathrm{B}>$

$</$ SPAN $>$

$</ \mathrm{P}>$

["foo 4 r", "AF-I", "Author=Plutarch; Work=Life of Artaxerxes; Locus= IV:5"], ...

\section{Apparatus referentium}

- When the text for the edition of a folio is prepared, references to works by other authors are wrapped in $<$ SPAN class=" Apparatus referentium" > elements

- During initialisation, an external file containing the apparatus referentium for the entire MS is read in and used to populate an internal data structure

- During DOM traversal, the $<\operatorname{SPAN}$...> elements have a trailing superscript with associated "onclick" handler grafted on

- When this handler is activated, the corresponding entry is retrieved using folio, face and $A R$ ordinal as keys, HTML elements are interpolated, and the record is displayed in the footnote area

- If the superscript is clicked a second time, the status ante bellum is restored 
Markup and data for apparatus referentium

$<\mathrm{P}>$

$<$ SPAN class= "App ref” style="content: 'Set: I; parts: 2"” > $<$ B class="L2 W7" $>$ laudemus $</$ B $>$ $<$ B class= "L2 W 8 " $>$ viros $</ \mathrm{B}>$ $</$ SPAN $>$ $</ \mathrm{P}>$ $<\mathrm{P}>$

$<$ SPAN class= "App ref” style="content: 'Set: I; parts: 2"” $>$ $<$ B class = " $\mathrm{L}_{3} \mathrm{~W}_{\mathrm{I}}$ " $>$ gloria $</ \mathrm{B}>\ldots<\mathrm{B}$ class $=$ " $\mathrm{L}_{3} \mathrm{~W} 8$ " $>$ sua $</ \mathrm{B}>$ $</ \mathrm{P}>$ $</$ SPAN $>$,

["foo 5 r", “AR-I", “Book=Ecclesiasticus; Locus=44:I”], . . .

\section{Feedback mechanism}

- If a stretch of text in the edition, transcription or translation is selected and the [Feedback] button clicked, a partially prepopulated web-mail form is displayed with the selected text occupying the "Text" field

- To accomplish this, the selected text must be captured before the [Feedback] button is clicked, as any click cancels the selection

- The [Feedback] button therefore has an "onmouseover" handler associated with it that retrieves any selected text and stores it in an internal data structure

- When the [Feedback] button is clicked, the contents of the internal data structure are retrieved and used to pre-populate the "Text" field of the web-mail form

Markup for [Feedback] button

$<\mathrm{TH}>$

$<$ INPUT

name="Feedback"

type="button"

value $=$ "Feedback"

class="active"

onMouseOver="CaptureSelectedText ()"

onClick="SendFeedback (Global.SelectedText)"

src="../Feedback/SendMail.aspx"

$>$

$</ \mathrm{TH}>$ 


\section{Capturing the view state}

- When any aspect of the view state is changed, the change is recorded in the query string component of the URL

- The query string records the folio, text variant, line numbering, reflow and debug states

function BookmarkCurrentState ()

var folio = document.getElementById ("Folio-selector").value var variant $=$ document.getElementById ("Text-selector").value var linenos = document.getElementById ("Lineno-selector").value var reflow = document.getElementById ("Reflow-selector").value window.location.search = "?" + "folio=" + folio + ";" + "text=" + variant + ";" + "linenos=" + linenos + ";" + "reflow=" + reflow + ";" + debug=" + Global.Debug

\section{Restoring the view state}

- If a query string is found in the URL from which the page is loaded, the view state is retrieved from the query string and used to re-construct the original view state

function RestoreState ()

$\operatorname{Dim}()$

GetParameters ()

document.getElementById ("Folio-selector").value = Global.Folio

SelectFolio (Global.Folio)

document.getElementById ("Text-selector").value = Global. Textclass

SelectText (Global.Textclass)

document.getElementById ("Lineno-selector").value = Global.

Linenos

SelectLinenos (Global.Linenos)

document.getElementById ("Reflow-selector").value = Global. Reflow

SelectReflow (Global.Reflow)

Brighten () 


\section{Optional line numbering}

- Space is reserved in the left margin of the text pane for possible line numbers

- All lines of a single text page are embedded in a surrounding $<$ DIV $>$ element

- When line-numbering is selected, this $\langle$ DIV $>$ is dynamically made a member of the "linenos" class in addition to any pre-existing class(es) such as "Edition", "Transcription" or "Translation"

- CSS rules prepend the current value of the CSS counter "linecounter" to each line within an element of class "linenos", and cause that counter to be incremented at each line boundary

- A further CSS rule causes that counter to be reset by the surrounding $<$ DIV > element

\section{Selecting line numbering}

$<\mathrm{TH}>$

$<$ SELECT id="Lineno-selector" name="Lineno-selector"

onChange $=$ "Dim (); BookmarkCurrentState ()">

$<$ OPTION value $=$ "Off" selected $>$ Line-nums: off $</ O P T I O N>$

$<$ OPTION value $=$ "On" $>$ Line-nums: on $</$ OPTION $>$

$</$ SELECT $>$

$</ \mathrm{TH}>$

\section{Reflow}

- The surrounding <DIV > of a text page indicates the class of the page ("Edition", “Transcription" or "Translation")

- If reflow is selected (possible only for Editions), the class is dynamically changed to reflect the reflow variant desired ("Reflowed-edition", "Fully-reflowed-edition")

- For both "Reflowed-edition" and "Fully-reflowed-edition", CSS rules change the "display" property of each line from "block" to "inline-block", thus allowing consecutive lines to run-on

- For "Reflowed-edition", a further CSS rule interpolates a red solidus between line boundaries and appends a red double-solidus to the last line 
Selecting a reflow variant

$<\mathrm{TH}>$

$<$ SELECT id="Reflow-selector" name="Reflow-selector"

onChange $=$ "Dim (); BookmarkCurrentState ()">

$<$ OPTION value $=$ "None" selected $>$ Reflow: none $</$ OPTION $>$

$<$ OPTION value="Normal" $>$ Reflow: normal $</ O P T I O N>$

$<$ OPTION value $=$ "Full" $>$ Reflow: full $</$ OPTION $>$

$</ \mathrm{TH}>$

$</$ SELECT $>$

\section{Commentaries and footnotes}

- Unlike the apparatus criticus, fontium \& referentium, commentaries (in the translation) and footnotes (in the supplementary material) are embedded in the page, not loaded from external files

- In the source of a translation, a stretch of text for which a commentary is available is embedded in a $<$ SPAN class= "Apparatus scholia"> element

- During DOM traversal, a superscript with associated "onclick ()" handler is grafted on whenever such an element is encountered

- Clicking the superscript will result in the commentary being displayed in the footnote area, and clicking it a second time will restore the status ante bellum

\section{Markup for commentaries}

$<$ DIV id="Translation" class="Translation fiv-4r" $>$

$<$ B class="RI" $>$ both because you do not consider such $\ldots</$ B $>$ $<$ SPAN class="Apparatus scholia" $>$

$<$ B class="R2" $>$ having been very well educated in it both in itself $</ \mathrm{B}>$

$<\mathrm{B}$ class= "R3" $>$ and as you are accustomed to engage also $\ldots</ \mathrm{B}>$;

$</$ SPAN $>$

$<$ B class="R4" $>$ and because your father the most famous ...</B $>$, $</ \mathrm{DIV}>$

$<$ DIV class= "Commentary" $>$

Elizabeth's education had benefited from the skills of a talented circle of humanist ... saying that she spoke the language 'frequently, willingly and moderately well'. $<$ DIV $>$ 


\section{Footnotes}

- Footnotes proper occur only in the supplementary material such as "The Author" rather than in the Electronic Edition per se.

- As the supplementary material is not subject to DOM traversal, explicit markup is required to indicate a footnote callout

- When the callout is clicked, the browser repositions the content to force the corresponding fragment to the top of the viewport, while a CSS rule ":target \{background: \#ffffc8; color: black; border: dotted I px\}" causes the target $<\mathrm{LI}>$ element to be discreetly highlit

- The JavaScript "onclick" event handler "SetReturn" receives the full URL of the target element as sole parameter and adds an "onclick" handler to the target element which, when activated, removes itself as "onclick" handler, and then calls "history.go (-I)" to return to the footnote callout

\section{Markup for footnotes}

Having received his BA in $\mathrm{I} 539$. . two years later. $<$ SUP class= "footnote" $><$ A href="\#ftnI" onClick="return SetReturn (this)" $>[\mathrm{I}]$ $</ \mathrm{A}></$ SUP $>$

$<$ OL style=" " >

$<$ LI id="ftnI" title=" " $>$ Anthony Wood, $<$ EM $>$ Athenae Oxonienses: an exact history of all the writers and bishops . . . I690</EM> (London I69I), p. I9I; Alfred B. Emden, $<$ EM $>$ A Biographical Register of the University of Oxford, A.D. I 50 I to I $540</ E M>$ (Oxford I974), p. I94.</LI>

$<\mathrm{LI}$ id="ftn2" title="” J. S. Brewer, James Gairdner and R. H. Brodie (eds.), . . </LI $>$

$</ \mathrm{OL}>$

\section{Full centering}

- Horizontal centering of web content is well understood and trivial to implement

- Vertical centering of such content, particularly when the height of the content is a priori unknown, is far less well understood and distinctly non-trivial to implement

- There are a number of mooted solutions, with all of which the one selected appears to compare favourably 
- The only known downside is that unless hidden from Dreamweaver (at least at version 8.0.2), it reliably causes the latter to crash from resource exhaustion

- The method chosen is based on prior work by Julien Cabanès, Chris Coyier and Michał Czernow

- The basis of the method is the use of the CSS property "display: inline-block" applied to the <BODY> element, together with use of the CSS pseudo-element ":before" to generate further "display: inline-block" content with "vertical-align: middle"

- The implementation is hidden from Dreamweaver by loading a subsequent stylesheet that over-rides the problematic properties

- This latter spreadsheet is then disabled by JavaScript, for which Dreamweaver has no interpreter

- As stylesheets cannot have an ID attribute, the "disabled" property is accessed via the stylesheet's index in the "document.styleSheets []" array

Implementing full centering

$<$ STYLE type="text/css">

body \{width: $99.9 \%$; overflow: auto; white-space:nowrap\}

body:before, div.MainContent \{vertical-align: middle\}

body, body:before, div.MainContent \{display: inline-block\}

body:before \{content: "; height: 99.9\%

body, div.MainContent \{text-align: center\}

html, body \{height: Io०\%

$</$ STYLE $>$

<SCRIPT type="text/javascript" >

document.styleSheets [4].disabled = true // Allow page to centre $</$ SCRIPT $>$

\section{Problems encountered during development}

- Highlighting very occasionally "sticks" in Internet Explorer, possibly as a result of a race hazard

- The inconsistent use of tonos and oxia caused much lost time

- Supporting the Chrome browser required the addition of one "!important" CSS rule

- Current browsers tend to inhibit use of "XMLHttpRequest ()" by default if files are requested from the local file system 
- MIME-type over-rides are also necessary if files are to be locally accessed

- Further problems resulting from local file access remain to be resolved (e.g., apparent corruption of HTML in dynamically loaded files)

\section{Further desiderata}

- Synchronised audio (or even audio/video), with each word highlit in MS and text as it is spoken (proof of concept already exists for audio; see below, n. 22)

- Simplify markup even further

- Generalise methodology to allow it to be easily applicable to other MSS

- Examine if/how methodology could be extended to accommodate multiple variant MSS

- Re-examine event handling to establish whether a race hazard is causing highlight sticking in IE

As mentioned above, Etheridge's Encomium was not delivered to Elizabeth I during her Royal Visit to Oxford in I 566 and it is doubtful whether she ever received it. This does not apply, however, in the case of our own electronic edition of the Encomium, which was presented to H.M. Queen Elizabeth II as a reminder of her and H.R.H. Prince Philip's Royal Visit to Royal Holloway, University of London on I4 March 20I4, when she graciously conferred a Regius Professorship in the Department of Music. This was one of twelve Regius Professorships bestowed on British Universities to mark the celebrations of the Diamond Jubilee on the occasion of the 6oth anniversary of Her Majesty's accession to the throne of the United Kingdom. In this way Etheridge's wish was somehow fulfilled, as his Encomium was at last received, amazingly enough on a similar occasion, by Elizabeth I's distinguished and homonymous successor almost 450 years later - better late than never! 


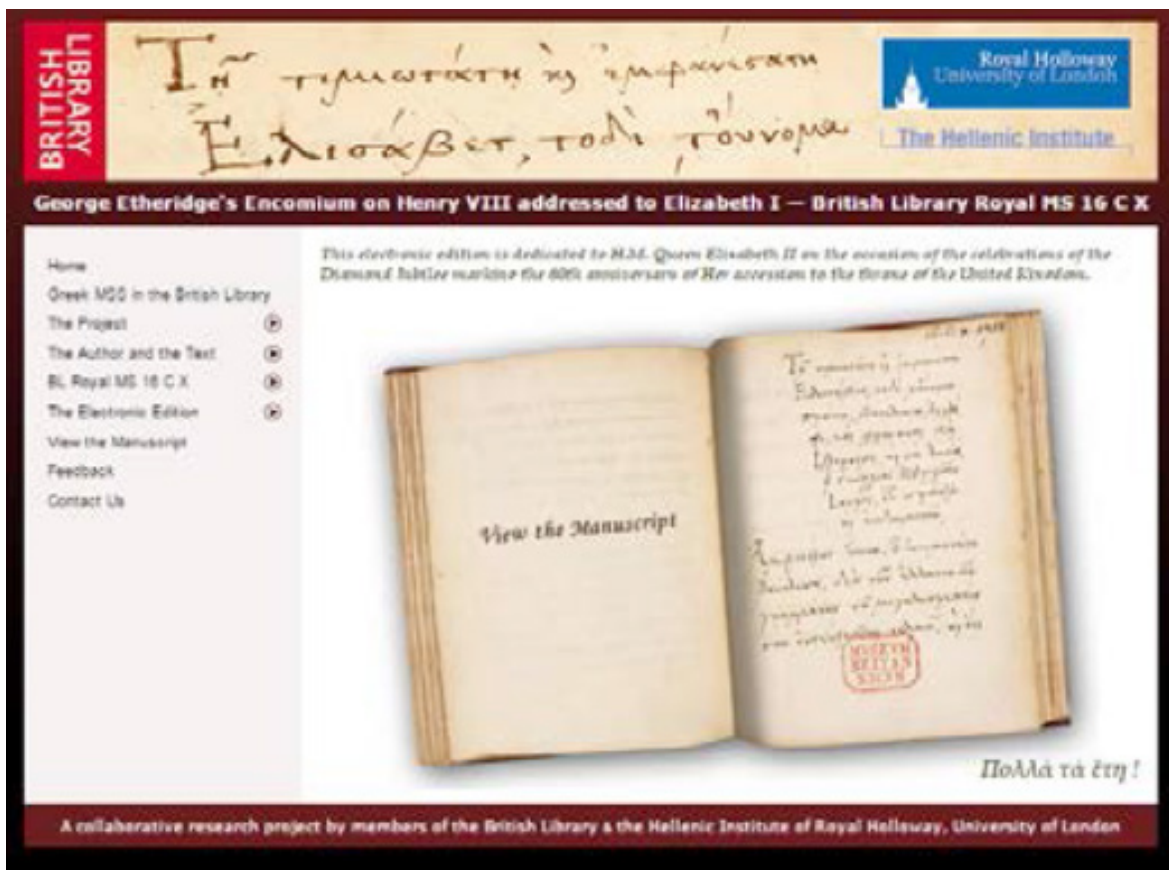

Figure 1. Hagiographical Texts in the Dominican Communication System.

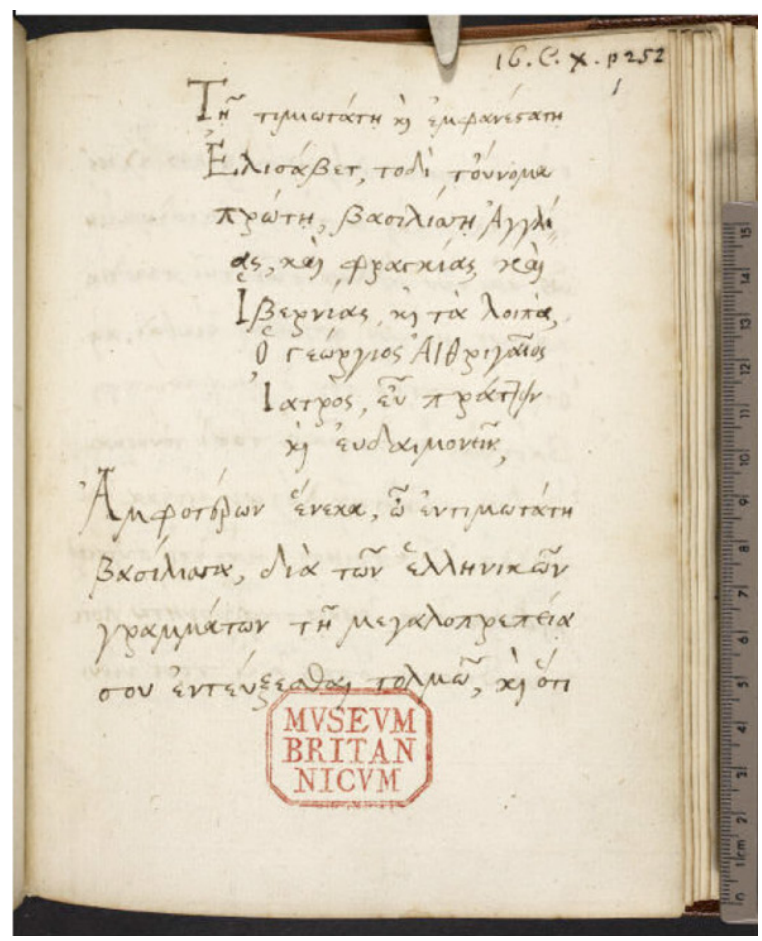

Figure 2. f. Ir (f. Ir.jpg) 


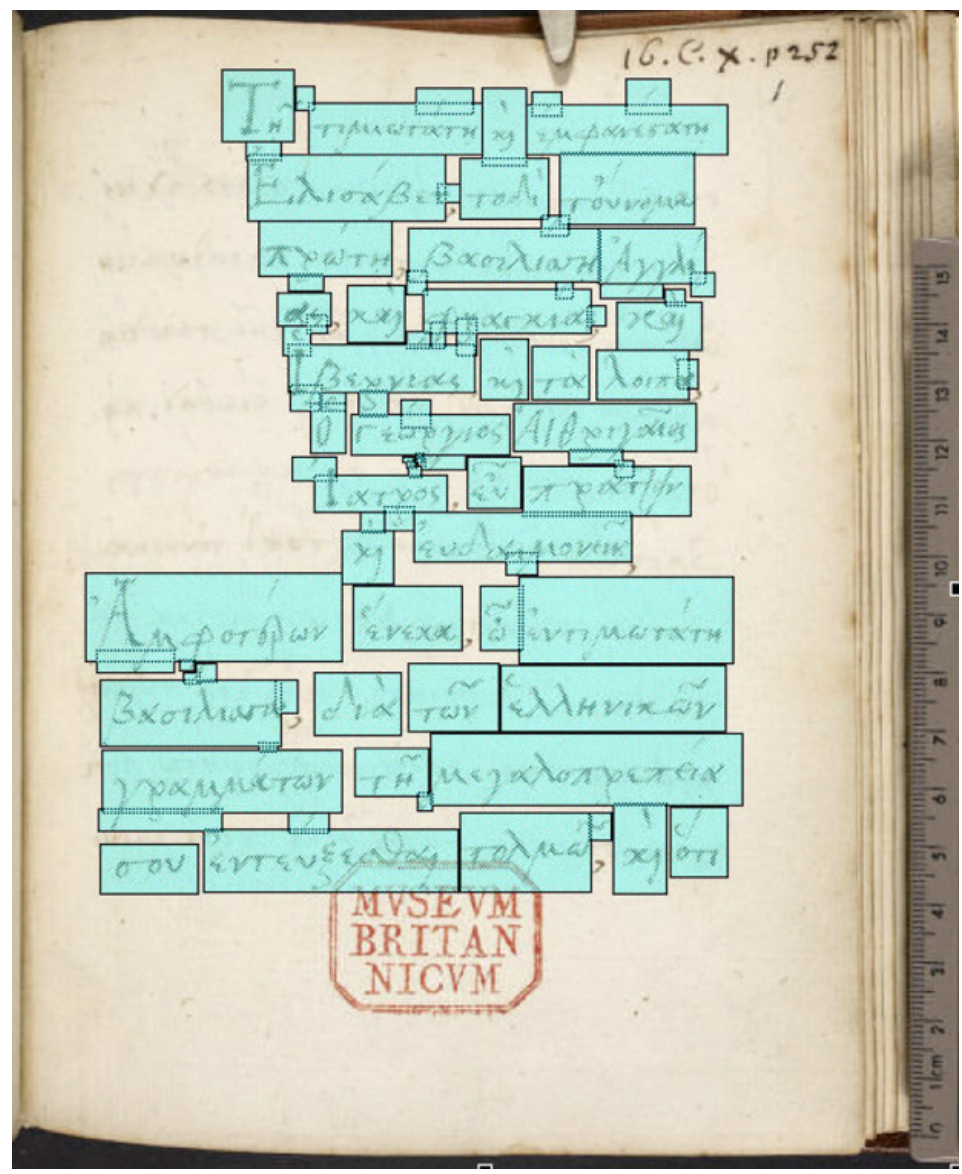

Figure 3. f. Ir, showing map areas (f. Ir-mapped-jpg)

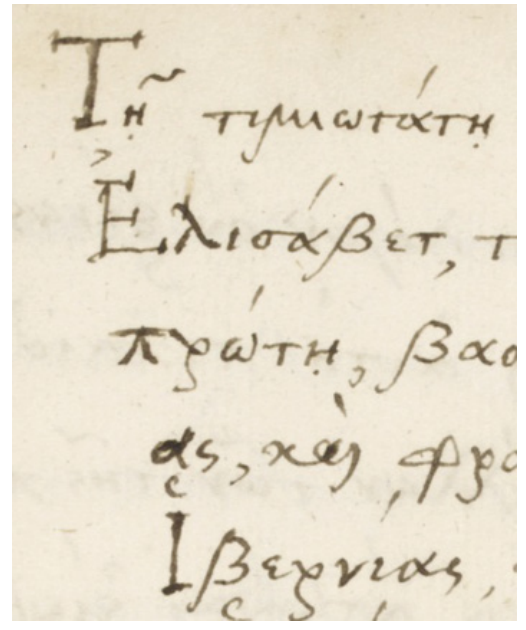

Figure 4. f. Ir (detail) (f.Ir-detail.jpg) 


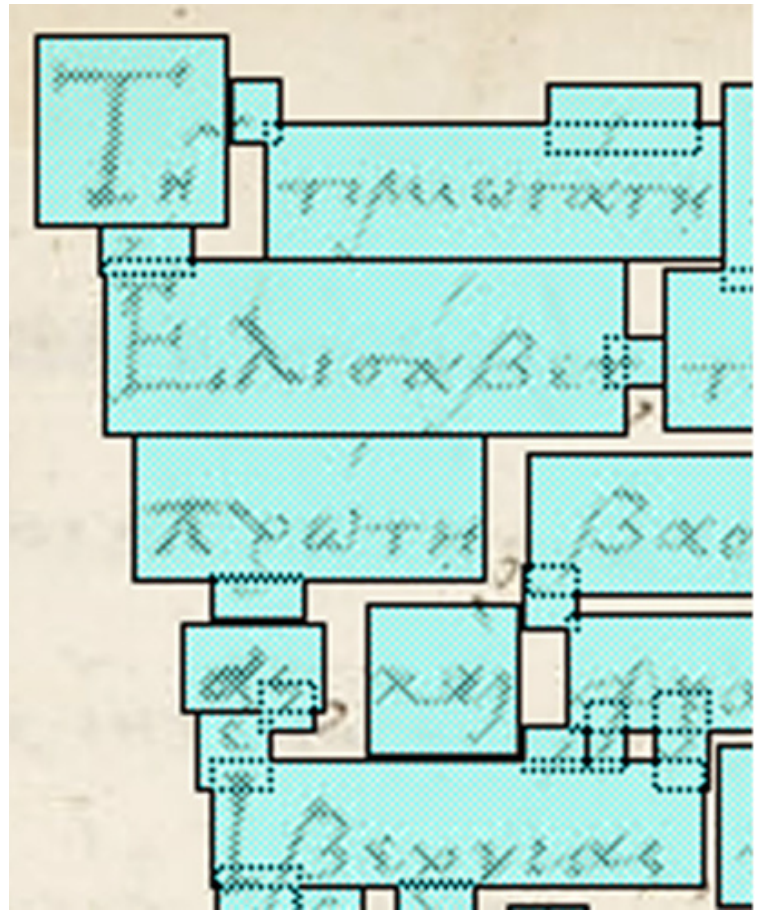

Figure 5. f. Ir (detail), showing map areas (f.Ir-detail-mapped.jpg)

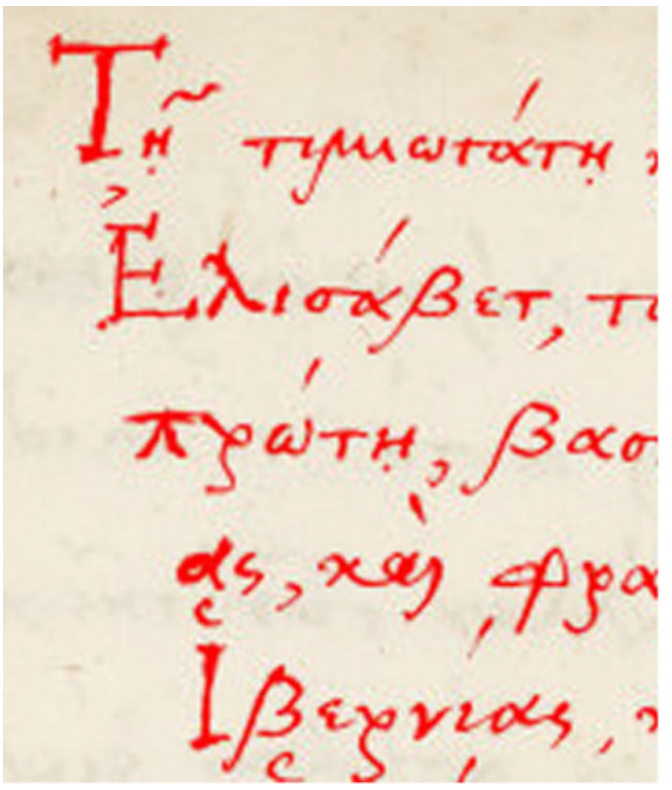

Figure 6. f. Ir (detail), showing red mask (f. Ir-detail-mask.jpg) 


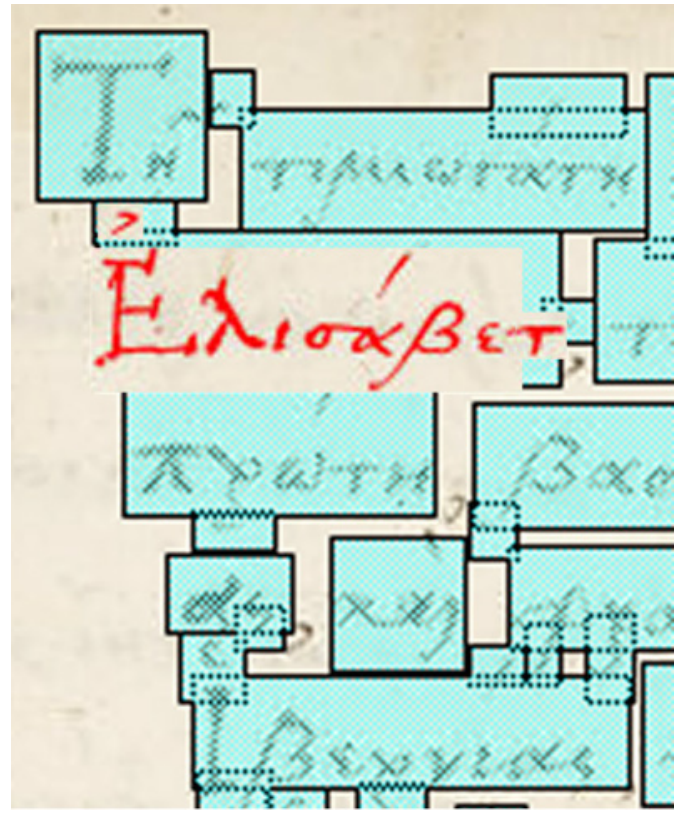

Figure 7. F. Ir (detail), showing mapped red mask (f.Ir-detail-mappedmask.jpg)

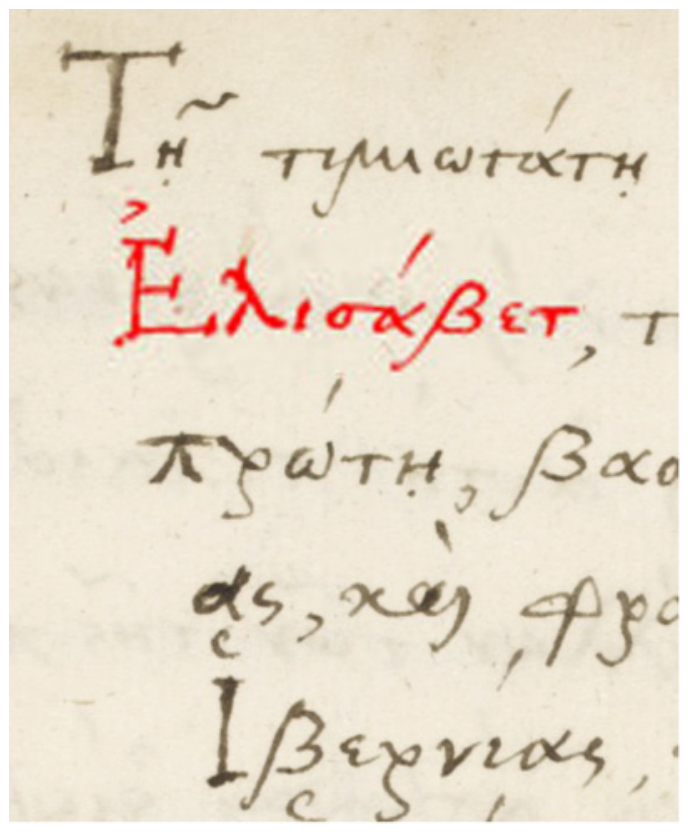

Figure 8. F. Ir, one word highlighted (f $\mathrm{r}$-detail-highlit.jpg) 


\section{Notes}

I. Evangelos Chrysos, 'Information Technology and Byzantine Studies', in

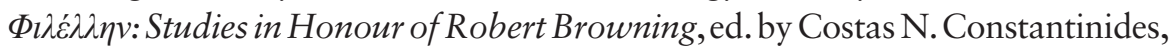
Nikolaos M. Panagiotakes, Elizabeth Jeffreys and Athanasios D. Angelou, Istituto Ellenico di Studi Bizantini e Postbizantini di Venezia, Bibliotheke, I7 (Venice, I996), pp. 43-53.

2. Jan M. Ziolkowski, 'De laude scriptorum manualium and De laude editorum: From Script to Print, From Print to Bytes', in Ars edendi Lecture Series, vol. I, ed. by Erika Kihlman and Denis Searby, Studia Latina Stockholmiensia, 56 (Stockholm, 20II), pp. 25-58.

3. For example, Elizabeth L. Eisenstein, The Printing Press as an Agent of Change: Communications and Cultural Transformations in Early-Modern Europe, 2 vols (Cambridge, I979), vol. I, pp. I4-I 5; Noël L. Brann, The Abbot Trithemius (I462-I 5 I6): the Renaissance of Monastic Humanism, Studies in the History of Christian Thought, 24 (Leiden, I98I).

4. De laude scriptorium pulcherimus tractatus domini Johannis Tritemij abbatis Spanbemensis ordinis sancti Benedicti de observancia Burkfeldensi ad Gerlacum abbatem Tuiciensem (Mainz, I492; revised edition, I497); ed. and German trans. by Klaus Arnold, Johannes Trithemius, De laude scriptorum: Zum Lobe der Schreiber, Mainfränkische Hefte, 6o (Würzburg, I973); English trans. by Roland Behrendt, Johannes Trithemius, In Praise of Scribes: De laude scriptorum (Lawrence, Kansas, I974); Italian trans. by Andrea Bernardelli, Giovanni Tritemio, Elogio degli amanuensi (Palermo, I997).

5. Joannis Trithemij, Spanheimensis, et Postea Divi Jacobi apud Herbipolim Abbatis, Viri suo cevo doctissimi, Tomus II. Annalium Hirsaugiensium, Opus nunquam hactenus editum, of ab Eruditis semper desideratum. Complectens Historiam Francice et Germanice, Gesta Imperatorum, Regum, Principum, Episcoporum, Abbatum, et Illustrium Virorum. Nunc primum in gratiam, o utilitatem Eruditorum è Manuscriptis Bibliothecoe Monasterij S. Galli public luci datum, Cum licentia Superiorum, Typis ejusdem Monasterij S. Galli, Anno MDCXC, Excudebat Joannes Georgius Schlegel, p. 42 I; quoted and trans. by Brann, The Abbot Trithemius, p. I46.

6. Johannes Trithemius, De laude scriptorum, Io, 24, ed. Arnold, Johannes Trithemius, p. 72 .

7. This explains why we opted for editionum rather than edendi in the title of this paper, as editio covers the meanings of both editing and publishing.

8. See Charalambos Dendrinos, 'Palaiologan Scholars at Work: Makarios Makres and Joseph Bryennios' Autograph', in From Manuscripts to Books. Proceedings of the International Workshop on Textual Criticism and Editorial Practice for Byzantine Texts (Vienna, IO-II December 2009) - Vom Codex 
zur Edition. Akten des internationalen Arbeitstreffens zu Fragen der Textkritik und Editionspraxis byzantinischer Texte (Wien, I0.-II. Dezember 2009), ed. by Antonia Giannouli and Elisabeth Schiffer, Veröffentlichungen zur Byzanzforschung, Band XXIX (Vienna, 20I I), pp. 36-38.

9. For a facsimile edition of the entire manuscript see Louise Durning ed. and Sarah Knight transl., Queen Elizabeth's Book of Oxford (Oxford, 2006). Digital images of certain folios are accessible online at: http://bodleian. thejewishmuseum.org/? $\mathrm{p}=50$.

Io. Penry Williams, 'Elizabethan Oxford: State, Church and University', in The History of the University of Oxford, vol. 3: The Collegiate University, ed. James McConica (Oxford, I986), pp. 397-440.

I I. Biographical information is based on Christopher Wright's articles, 'The Author' and 'The Text', both accessible at: http://hellenic-institute.rhul.ac.uk/ Research/Etheridge/Author-and-Text/Author.html and http://hellenic-institute. rhul.ac.uk/Research/Etheridge/Author-and-Text/Text.html.

I2. Accessible at: http://codexsinaiticus.org/en/manuscript.aspx.

I3. Accessible at: http://hellenic-institute.rhul.ac.uk/Research/Etheridge/.

I 4. Accessible at: http://hellenic-institute.rhul.ac.uk/Research/Etheridge/ British-Library/Greek-MSS.html.

I 5 . See above, note I I.

I6. Accessible at: http://hellenic-institute.rhul.ac.uk/Research/Etheridge/ Manuscript/BL-Royal-MS- I6-C-X.html.

I7. Accessible at: http://www.bl.uk/manuscripts/FullDisplay.aspx?ref=Royal_ MS_I6_C_X.

I 8. Accessible at: http://hellenic-institute.rhul.ac.uk/Research/Etheridge/ Electronic-Edition/User-Guide.shtml.

I 9. Accessible at: http://hellenic-institute.rhul.ac.uk/Research/Etheridge/ Electronic-Edition/Editorial-Principles-and-Conventions.html.

20. Accessible at: http://hellenic-institute.rhul.ac.uk/Research/Etheridge/ Electronic-Edition/Technical-Aspects.html.

2I. See W.S. Allen, Vox Graeca (Cambridge, I99 I³), pp. I25-I34.

22. A foretaste of the synchronised audio-textual rendition of the opening words of Etheridge's manuscript is accessible at: http://hellenic-institute.rhul. ac.uk/Research/Synch/Greek.html.

\section{Bibliography}

Allen, W.S., Vox Graeca (Cambridge, I99 ${ }^{3}$ ) 
Brann, Noël L., The Abbot Trithemius (I462-I5I6): the Renaissance of Monastic Humanism, Studies in the History of Christian Thought, 24 (Leiden, I98I)

Chrysos, Evangelos, 'Information Technology and Byzantine Studies', in

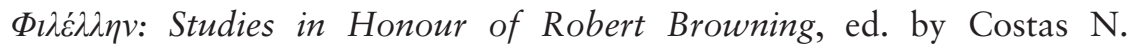
Constantinides, Nikolaos M. Panagiotakes, Elizabeth Jeffreys and Athanasios D. Angelou, Istituto Ellenico di Studi Bizantini e Postbizantini di Venezia, Bibliotheke, I7 (Venice, I996), pp. 43-53

Dendrinos, Charalambos, 'Palaiologan Scholars at Work: Makarios Makres and Joseph Bryennios' Autograph', in From Manuscripts to Books. Proceedings of the International Workshop on Textual Criticism and Editorial Practice for Byzantine Texts (Vienna, IO-II December 2009) - Vom Codex zur Edition. Akten des internationalen Arbeitstreffens zu Fragen der Textkritik und Editionspraxis byzantinischer Texte (Wien, IO.-II. Dezember 2009), ed. by Antonia Giannouli and Elisabeth Schiffer, Veröffentlichungen zur Byzanzforschung, Band XXIX (Vienna, 20I I), pp. 36-38

Durning, Louise, ed. and Sarah Knight transl., Queen Elizabeth's Book of Oxford (Oxford, 2006)

Eisenstein, Elizabeth L., The Printing Press as an Agent of Change: Communications and Cultural Transformations in Early-Modern Europe, 2 vols (Cambridge, I979)

Johannes Trithemius, De laude scriptorium pulcherimus tractatus domini Johannis Tritemij abbatis Spanbemensis ordinis sancti Benedicti de observancia Burkfeldensi ad Gerlacum abbatem Tuiciensem (Mainz, I492; revised edition, I497)

Johannes Trithemius, De laude scriptorum: Zum Lobe der Schreiber, ed. and German transl. by Klaus Arnold, Mainfränkische Hefte, 60 (Würzburg, I973)

Johannes Trithemius, In Praise of Scribes: De laude scriptorum, English trans. by Roland Behrendt (Lawrence, Kansas, I974)

Giovanni Tritemio, Elogio degli amanuensi, Italian transl. by Andrea Bernardelli (Palermo, I997)

Williams, Penry, 'Elizabethan Oxford: State, Church and University', in The History of the University of Oxford, vol. 3: The Collegiate University, ed. James McConica (Oxford, I986), pp. 397-440

Wright, Christopher, 'The Author' and 'The Text', at: http://hellenic-institute. rhul.ac.uk/Research/Etheridge/Author-and-Text/Author.html and http:// hellenic-institute.rhul.ac.uk/Research/Etheridge/Author-and-Text/Text. html respectively 
Ziolkowski, Jan M., 'De laude scriptorum manualium and De laude editorum: From Script to Print, From Print to Bytes', in Ars edendi Lecture Series, vol. I, ed. by Erika Kihlman and Denis Searby, Studia Latina Stockholmiensia, LVI (Stockholm, 20I I), pp. 25-58 